\title{
Rapid onset obesity, hypoventilation, hypothalamic, autonomic and thermal dysregulation, and neural tumour (ROHHADNET) syndrome presenting with Cushing syndrome
}

\author{
S P Sumanasena ${ }^{1}$, S de Silva ${ }^{2}$, I Perera $^{3}$, A Sudeen $^{3}$, R Wasala ${ }^{3}$ \\ Ceylon Medical Journal 2012; 57: 47-48
}

\section{Introduction}

Rapid onset obesity, hypoventilation, hypothalamic, autonomic and thermal dysregulation, and neural tumours constitute a rare but distinct clinical syndrome (ROHHADNET) [1,2]. This commonly presents with obesity, but rapidly progresses to cardio-respiratory arrest and death in childhood if inappropriately managed.

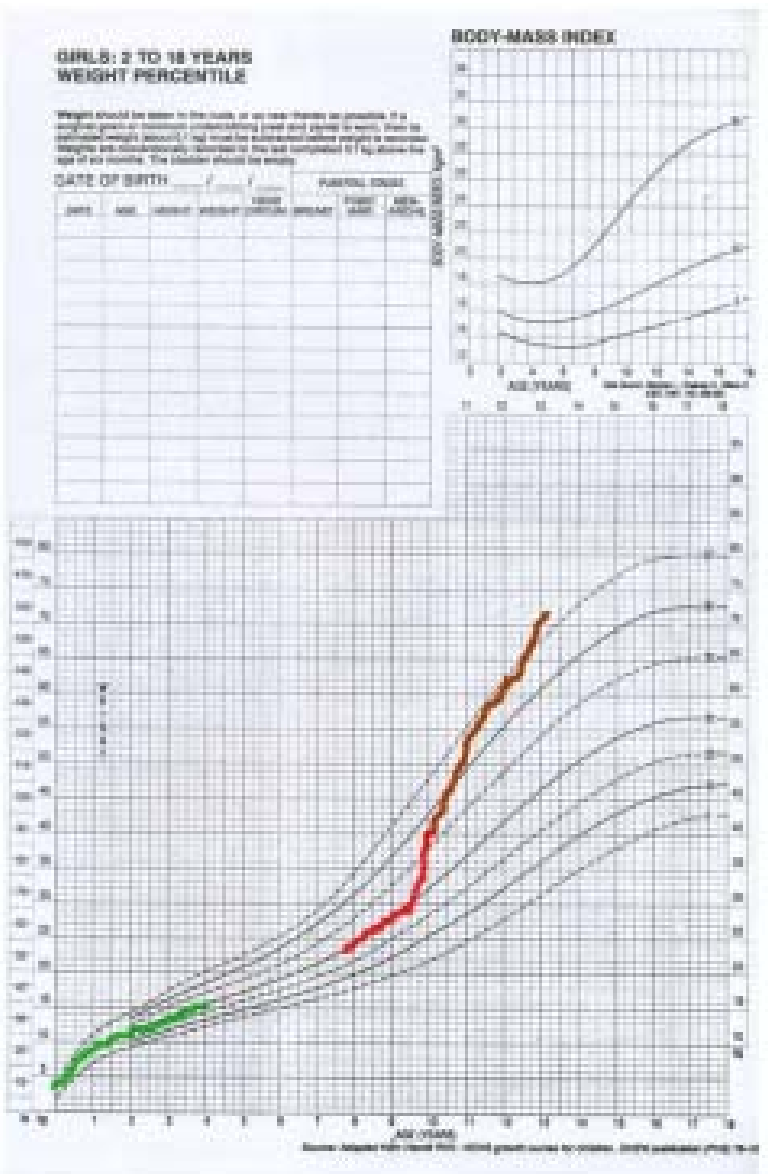

Figure 1. The weight chart.

\section{Case report}

A 10-year old girl presented with progressive difficulty in breathing and body swelling for two weeks and rapidly progressed to respiratory arrest requiring ventilation. Following recovery she had recurrent respiratory failure, predominantly in the mornings. Progressive drowsiness, hallucinations and a temperature rise preceded each episode.

Parents reported behavioural changes and deterioration in school work for six months. A rapid weight gain of $6 \mathrm{~kg}$ disproportionate to height achievement was documented over a period of three months associated with a ravenous appetite (Figure 1).

Examination revealed a pre pubertal cushinoid girl with no virilisation or palpable abdominal masses and with normal cardiovascular and neurological systems. Serial arterial blood gases showed progressive respiratory acidosis with gradual carbon dioxide $\left(\mathrm{CO}_{2}\right)$ accumulation followed by hypoxia. Basic haematology, renal and liver functions were normal. Serum electrolytes showed hypernatraemia, and hypokalaemia (Na 167, K 3.1 meq/1).

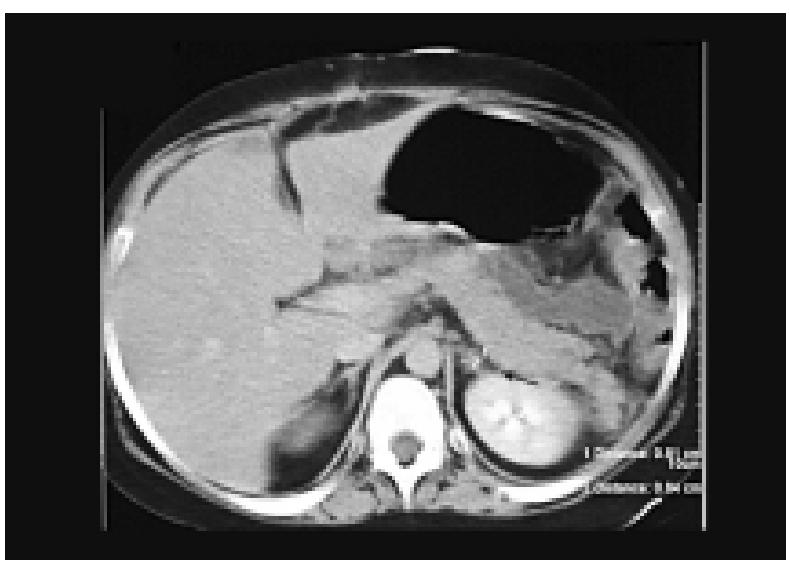

Figure 2. The CT abdomen with the ganglioneuroma.

${ }^{1}$ Department of Paediatrics, Faculty of Medicine, University of Colombo, Sri Lanka, ${ }^{2}$ Intensive Care Unit, Lady Ridgeway Hospital for Children, Colombo, Sri Lanka, ${ }^{3}$ Paediatric Unit, Sri Jayewardenepura Hospital, Colombo, Sri Lanka.

Correspondence: SPS, e-mail: <samanmalis@yahoo.com>. Received 27 June and revised version accepted 22 October 2011. Competing interests: none declared. 
Basal cortisol levels ( 8 am: $20 \mathrm{~g} / \mathrm{ml}, 12$ mid night: 19.2 $\mathrm{g} / \mathrm{ml}$ ) showed an altered diurnal rhythm. A low dose dexamethasone suppression test did not significantly suppress cortisol (pre $8 \mathrm{am} 20 \mathrm{~g} / \mathrm{ml}$, post $8 \mathrm{am} 13.8 \mathrm{~g} / \mathrm{ml}$ ) confirming Cushing syndrome. A negative high dose dexamethasone suppression test suggested the stimulation above the level of the pituitary (pre $324 \mathrm{~g} / \mathrm{ml}$, post $172 \mathrm{~g} / \mathrm{ml}$ ) [6]. ACTH (27.5pg/ml), TSH, LH, FSH and prolactin levels were normal. Corticotrophin releasing hormone (CRH) levels and CRH stimulation test could not be done in Sri Lanka.

A magnetic resonance imaging showed normal hypothalamo pituitary region. The $\mathrm{CT}$ scan of the abdomen showed a hypodense area in the region of the left adrenal (Figure 2). Left adrenalectomy and two small tumours adjacent to the left adrenal gland $(0.6 \times 0.2 \mathrm{~cm}$ and $0.7 \times 0.5 \mathrm{~cm})$ and a larger retroperitoneal mass $(3 \times$ $3 \mathrm{~cm}$ ) were resected. Histologically and histochemically these were confirmed as endocrinologically silent ganglioneuromas. Adrenal gland showed mild hyperplasia.

Serial respiratory rate, blood gases and pulseoximetry confirmed depression of respiratory rate and effort during sleep state and absence of a ventilatory response to $\mathrm{CO}_{2}$ accumulation. She recorded $\mathrm{CO}_{2}$ levels as high as $124 \mathrm{mmHg}$ with $\mathrm{CO}_{2}$ as low as $35 \mathrm{mmHg}$. Obstructive sleep apnoea, myasthenia gravis and myopathies were excluded.

An internet search with key words hypoventilation, cushing syndrome, and ganglioneuroma helped in arriving at a diagnosis of Late Onset Central Hypoventilation Hypothalamic Dysfunction Syndrome (LO-CH/HD) later named as ROHHADNET [2,3].

\section{Discussion}

Recurrent respiratory failure, hypothalamic dysfunction and neural crest tumours were first described in newborns with congenital central hypoventilation syndrome (CCHS) [4]. In contrast to CCHS, children with ROHHADNET remain healthy in early childhood and do not possess the specific disease causing paired-like homeobox gene (PHOX2B). Rapid onset obesity is a constant denominator in all reported cases [1, 2, 5]. Embryological proximity of the neuro endocrine systems and the insensitivity of the respiratory centre to the accumulation of $\mathrm{CO}_{2}$ are postulated in the pathogenesis but the exact mechanism is under investigation [3].

Our patient demonstrated all key features displayed in this rare syndrome-obesity, hypoventilation, hypothalamic dysfunction, neuro developmental disturbances and ganglioneuromas [1,2,5]. Cushing syndrome was reported only in one previous case but all biochemical and histological features were remarkably similar to our case [1].

Investigations and clinical manifestations suggested hypercortisolism as a result of excess $\mathrm{CRH}$ of hypothalamic origin but confirmation was not feasible due to unavailability of inferior petrosal venous sampling.

The structured approach enabled a clinical diagnosis and appropriate management. Good ventilatory support and symptomatic management are beneficial. Deaths are due to ventilation associated complications, endocrine or autonomic crisis [5]. Though home ventilation was a successful step, the lack of continuous community based care led to severe pneumonia and death.

\section{References}

1. Bougnères $P$, Pantalone L, Linglart A, Rothenbühler A, Le StunffC. Endocrine manifestations of the rapid-onset obesity with hypoventilation, hypothalamic, autonomic dysregulation, and neural tumor syndrome in childhood. Journal of Clinical Endocrinology Metabolism 2008; 93: 3971-80.

2. Ize-Ludlow D, Gray JA, Sperling MA, et al. Rapid-onset obesity with hypothalamic dysfunction, hypoventilation, and autonomic dysregulation presenting in childhood. Pediatrics 2007; 120: 179-88.

3. Katz ES, McGrath S, Marcus CL. Late-onset central hypoventilation with hypothalamic dysfunction: a distinct clinical syndrome. Pediatric Pulmonology 2000; 29: 62-8.

4. Swaminthan S, Gilsanz V, Atkinson J, Keens TG. Congenital central hypoventilation syndrome associated with multiple ganglioneuromas. Chest 1989: 96: 423-4.

5. Trang $\mathrm{H}$, Laudier $\mathrm{B}$, Trochet $\mathrm{D}$, et al. $\mathrm{PHOX} 2 \mathrm{~B}$ gene mutation in a patient with late-onset central hypoventilation. Paediatric Pulmonology 2004; 38: 349-51.

6. Stewart PM. The adrenal cortex. In: Larsen PR, Kronenberg HM, Melmed S, Polonsky KS eds. In: Williams Textbook of Endocrinology 10th Ed. Saunders, 2003; 491-551. 